\title{
An Intervention Program Targeting Daily Adaptive Skills Through Executive Function Training for Adults with Autism Spectrum Disorder: A Pilot Study
}

\author{
Joo Hyun Kim ${ }^{1 *}$, Young Ah Kim ${ }^{1 *}$, Da-Yea Song ${ }^{1}$, Hwi Bin Cho', Han Bit Lee', \\ Ji Hye Park', Jung In Lim², Min Hee Hong ${ }^{3}$, Paul Kyuman Chae ${ }^{4}$, and Hee Jeong Yoo ${ }^{1,5} \bowtie$ \\ ${ }^{1}$ Department of Psychiatry, Seoul National University Bundang Hospital, Seongnam, Republic of Korea \\ ${ }^{2}$ Korea VHS (Veterans Health Service) Medical Center, Seoul, Republic of Korea \\ ${ }^{3}$ BomBom ABA, Seongnam, Republic of Korea \\ ${ }^{4}$ Korean Psychological Health Institute, Seoul, Republic of Korea \\ ${ }^{5}$ Department of Psychiatry, Seoul National University College of Medicine, Seoul, Republic of Korea
}

Objective Adults with autism spectrum disorders (ASD) experience significant difficulties with executive functioning (EF) and related adaptive skills, yet the lack of interventions in South Korea targeting these areas has resulted in a heightened need to develop an evidence-based program. Therefore, we developed a novel intervention aiming to enhance everyday EF and daily adaptive skills in adults with high-functioning ASD and conducted a pilot study to evaluate the validity and feasibility of the program.

Methods A behavioral intervention of 10-weekly sessions was developed based on literature searches and focus group interviews. Seven adults with high-functioning ASD (mean age=20.29) participated in a single-group pilot trial. We used self and parent-report questionnaires as well as skills measured by assessment instruments to analyze differences before and after the intervention.

Results Significant improvements were shown in everyday EF, including time management, organization, self-restraint, and regulation of emotions. Additionally, results demonstrated an enhancement in adaptive functioning, especially in the subdomains of daily living skills. Analyses of parental outcomes only revealed a significant decrease in the scores of emotion regulation.

Conclusion The current study provides good evidence for the validity and feasibility of an intervention to improve everyday EF and adaptive skills in adults with ASD.

Psychiatry Investig 2021;18(6):513-522

Key Words Autism spectrum disorders, Executive function, Adaptive skills, Behavioral intervention.

\section{INTRODUCTION}

Autism spectrum disorder (ASD) is a lifelong condition characterized by social communication deficits with restricted and repetitive interests or behaviors. Co-occurring disorders are more common in individuals with ASD than in the general population. ${ }^{1}$ While developmental trajectories do differ based on cognitive abilities, Baio et al. ${ }^{2}$ found that $70 \%$ of

Received: December 4, 2020 Revised: March 6, 2021

Accepted: March 21, 2021

$\square$ Correspondence: Hee Jeong Yoo, MD, PhD

Department of Psychiatry, Seoul National University Bundang Hospital, 82

Gumi-ro 173beon-gil, Bundang-gu, Seongnam 13620, Republic of Korea

Tel: +82-31-787-7436, Fax: +82-31-787-4058, E-mail: hjyoo@snu.ac.kr

*These authors contributed equally to this work.

(c) This is an Open Access article distributed under the terms of the Creative Commons Attribution Non-Commercial License (https://creativecommons.org/licenses/bync/4.0) which permits unrestricted non-commercial use, distribution, and reproduction in any medium, provided the original work is properly cited. the individuals with ASD do not have an intellectual disability. However, despite the need for treatment and services, these individuals are often overlooked and considered to be coping with conventional situations and environments. ${ }^{3.4}$ For this reason, this group of high-functioning adults with ASD is placed at a blind spot by being generally less understood and with a shortage of appropriate support. ${ }^{5}$

One area where individuals with ASD experience daily difficulties involves atypical processing in executive functioning (EF). EF is used to control an individual's behavior to achieve the chosen goals, including working memory, cognitive flexibility, attentional control, emotion regulation, organizational skills, response inhibition, planning, and problem-solving. ${ }^{6-8}$ While EF is generally measured by neuropsychological evaluations, previous studies have raised concerns about its ability to assess the performance of EF skills in real-world settings. ${ }^{9}$ To overcome these shortcomings, the term 'everyday EF' has 
been used to consider the cognitive components of EF from an ecological perspective. ${ }^{10}$ Compared to age and IQ-matched neurotypical peers, children with ASD show impairments in everyday EF, such as initiation, response flexibility, control inhibition, planning, and working memory. ${ }^{11,12}$ Studies with adults also found deficiencies in EF among the ASD group compared to healthy control groups when using the Wisconsin Card Sorting Test to measure cognitive flexibility. ${ }^{13}$ Others have reported that high-functioning adults with ASD demonstrate deficits in hot and cold EF areas such as emotional awareness, theory of mind, working memory, and response initiation and suppression. ${ }^{14}$

A successful transition into adulthood mostly requires complex skills based on EF, such as managing unexpected changes or situations in academic or workspace settings, controlling emotional response, and independent time-management. ${ }^{15}$ Even among adults with ASD who have higher cognitive abilities, deficits in EF such as spending too much or too little time planning and carrying out tasks and focusing on details can contribute to inefficient performance habits. ${ }^{15}$ Additionally, high-functioning adults with ASD experience difficulties reflecting on their behaviors, which can unintentionally cause discomfort to people around them. ${ }^{16}$ Parental and academic support lessens as one leaves school to continue with higher education or start a job, and the expectation of planning and working independently can be especially problematic for individuals with ASD who have deficits in everyday EF.

Adaptive functioning is the ability to apply behavioral skill sets required for self-care and independence to the demands in everyday life. ${ }^{17}$ It involves the performance of appropriate conceptual (i.e., communication), practical (i.e., daily living activities), and social skills (i.e., following social rules). ${ }^{18}$ Individuals with ASD experience difficulties in everyday EF that are often associated with significant impairments in adaptive functioning. ${ }^{19}$ Adaptive skills deficits increase with age and are prominent in young adults with ASD. ${ }^{17,20}$ For instance, it could affect personal hygiene, being on time for lectures and meetings, taking care of the housework, and other skills needed for independent living. ${ }^{21}$ Therefore, there is a desperate need for an effective intervention targeting improvement in everyday EF to develop adaptive functioning and, as a result, help individuals with ASD successfully transition into adulthood.

Although several intervention programs aim to improve adaptive skills and provide academic/employment support for adults with ASD, ${ }^{22-24}$ only a few studies have investigated interventions to improve everyday EF skills in adults with ASD and are limited due to inconclusive results. Pugliese and White ${ }^{25}$ applied cognitive behavioral therapy to improve problemsolving skills and found clinically significant improvements in two out of five participants. White et al. ${ }^{26}$ compared a virtu-
al-reality-Brain-Computer-Interface intervention and a psychosocial intervention developed for college students with ASD to improve EF skills and college adaptation. Unfortunately, these previous studies failed to provide a strong evidence base for an intervention program due to its small sample size and mixed results.

Two studies have provided positive evidence for interventions that can improve EF skills in adults with ASD. Eack et al. ${ }^{27}$ studied the efficacy of Cognitive Enhancement Therapy (CET) on neurocognitive skills such as processing speed, working memory, problem-solving and cognitive flexibility on 14 adults with ASD and found significant improvements in those areas. The Supported Employment, Comprehensive Cognitive Enhancement, and Social Skills (SUCCESS) intervention focused on EF, memory skills, social cognition, and communication skills. ${ }^{28}$ Overall, the pilot study for the SUCCESS intervention provided good preliminary evidence that behavioral interventions can improve EF skills in adults with ASD.

Despite the preliminary evidence of support programs for adults with ASD emerging in the US, such resources are still scarce in South Korea. To address such needs, we developed a cost and time-effective intervention program targeting improvements in everyday EF and adaptive functioning to help individuals with ASD successfully transition into adulthood. Therefore, we conducted a pilot study in preparation for a randomized controlled trial to investigate the validity and feasibility of the intervention program. We hypothesized that the participants would show an improvement in everyday EF and adaptive functioning after the intervention.

\section{METHODS}

\section{Developing the intervention}

The program content and structure were formulated by referencing relevant literature based on cognitive deficits and behavioral intervention strategies, emphasizing transition-age adults with ASD or improvements in EF. A focus group interview (FGI) was administered to better understand the daily difficulties experienced by adults with ASD (IRB No.: B-1904537-302). Participants were recruited from the psychiatry outpatient clinic at the Seoul National University Bundang Hospital (SNUBH) and through posters distributed by email and posted on bulletin boards of public institutions or online communities. Thirty-nine individuals, composed of 16 adults with ASD, 12 parents of adults with ASD, and 11 professionals who frequently work with adults with ASD, participated in a total of eight interviews (Table 1).

Interview questions were created based on the following topics: 1) common problems adults with ASD face in every- 
Table 1. Demographic information of the participants of the Focus Group Interview

\begin{tabular}{|c|c|c|c|c|c|c|}
\hline $\begin{array}{l}\text { Participant } \\
\text { group }\end{array}$ & $\mathrm{N}$ & $\begin{array}{l}\text { Age } \\
\text { range }\end{array}$ & Sex & Education & Occupation & $\begin{array}{c}\text { Range of } \\
\text { interview duration }\end{array}$ \\
\hline Adults & 16 & $19-32$ & $16 \mathrm{M}$ & $\begin{array}{l}\text { High school graduate- } \\
\text { Doctoral level graduate }\end{array}$ & $\begin{array}{l}\text { Unemployed, university student, } \\
\text { research assistant, office worker and others }\end{array}$ & $90-110$ \\
\hline Caregivers & 12 & $47-61$ & $12 \mathrm{~F}$ & $\begin{array}{l}\text { Middle school graduate- } \\
\text { Master's level graduate }\end{array}$ & $\begin{array}{l}\text { Housewife, office worker, nutritionist, tutor, } \\
\text { ensemble leader, caregiver and others }\end{array}$ & $110-150$ \\
\hline Professionals & 11 & $28-52$ & $2 \mathrm{M}, 9 \mathrm{~F}$ & $\begin{array}{l}\text { University graduate- } \\
\text { Doctoral level graduate }\end{array}$ & $\begin{array}{l}\text { Social worker, special education teacher, } \\
\text { development center director, foundation } \\
\text { secretary-general, centre director, culinary } \\
\text { therapist, NGO café administrator }\end{array}$ & $90-150$ \\
\hline Total & 39 & $19-61$ & $18 \mathrm{M}, 21 \mathrm{~F}$ & & & $90-150$ \\
\hline
\end{tabular}

Adults: adults with ASD, Caregivers: caregivers of adults with ASD, Professionals: professionals who work with adults with ASD, M: male, F: females, ASD: autism spectrum disorders, NGO: non-governmental organization

day life situations (excluding those related to the core ASD symptoms), 2) EF related difficulties experienced by adults with ASD, 3) methods in which adults with ASD can be assisted, and 4) suggestions on the appropriate duration and length of an intervention program. We conducted a thematic analysis to analyze the interview results based on the qualitative data analysis methods suggested by Miles and Huberman. ${ }^{29}$ We organized the responses into categories and resulted in ten topics to cover during the intervention.

\section{Intervention content and structure}

We designed the intervention for 6-8 participants to ensure adequate opportunities to participate and provide enough time for activities. Based on the literature search and the results of the FGI, we formulated ten intervention contents. The first half of the sessions target EF skills in organization (i.e., setting goals), planning (i.e., prioritizing activities), time management (i.e., setting a daily schedule, prioritizing activities), emotion regulation (i.e., managing anxiety, anger, stress), and cognitive flexibility (i.e., changing fixed patterns of behavior, adapting to situations). The latter sessions emphasize the application of the taught skill sets in daily adaptive settings. The sessions focus on personal hygiene, health, diet, safety, financial management, adaptation to new environments, job searching, preparing for applications or interviews, and ways to maintain an effective work environment to support adults with ASD become independent. The intervention program included ten weekly two hour sessions with 10-minute breaks in between. The program administrator, a registered clinical psychologist, led the intervention and was assisted by two other clinical psychologists and two research assistants. Each session started with reviewing the previous week's assignments and a discussion question to promote critical thinking regarding the next topic. The lesson material was delivered in a lecture-like format with detailed methods to apply specific EF skills by the administrator with PowerPoint presentations. We handed out worksheets with practice activities to apply the materials covered during the lesson to participants. While each individual completed some activities independently, others required a group discussion between $2-3$ participants under close supervision. The session ended by introducing the assignments due the following week. After the session, all participants were given an assessment sheet to express their perceived satisfaction and difficulty level of the session. Table 2 describes the contents of each session in detail.

\section{Participants}

This pilot study was a single group pre-posttest design, in which all participants received the intervention. The recruitment was advertised by posters on bulletin boards at SNUBH. Digital posters were also sent to online forums for individuals with developmental disorders and their families, in addition to emails sent to experts and professionals who work with young adults with ASD. A screening interview was conducted via telephone to assess the inclusion and exclusion criteria. The inclusion criteria for the participants were 1) a clinical diagnosis of ASD by a certified child and adolescent psychiatrist based on the Autism Diagnostic Observation Schedule (ADOS) and the Autism Diagnostic Interview-Revised (ADI-R), 2) adults over 18 years old, 3) and have previously been tested on the WAIS-IV with a full-scale (FSIQ) score over 70 to ensure that participants would be able to follow the lecture-style session independently. Any clinically significant behavioral problems, emotion regulation problems, psychotic symptoms, risk of self-harm, or harm to others that could disrupt the group setting were caught during by the screening assessments and interviews. This study was approved by the Institutional Review Board of SNUBH (IRB No. B-1910-572-302) and registered with clinicaltrials.gov (NCT04418492). All participants and their caregivers provided written informed consent. 
Table 2. Program topic and lesson content by session

\begin{tabular}{|c|c|c|c|}
\hline Session & $\mathrm{EF}$ areas & Topic & Lesson content \\
\hline 1 & $\begin{array}{l}\text { Strengthening motivation } \\
\text { and setting goals }\end{array}$ & $\begin{array}{l}\text { Finding out about } \\
\text { my executive function } \\
\text { abilities }\end{array}$ & $\begin{array}{l}\text { - Introducing the program and its goals } \\
\text { - Understanding what executive functions are } \\
\text { - Setting goals using a person-centered plan }\end{array}$ \\
\hline 2 & $\begin{array}{l}\text { Planning and } \\
\text { organization }\end{array}$ & $\begin{array}{l}\text { Making personalized } \\
\text { plans and systems }\end{array}$ & $\begin{array}{l}\text { - Making plans to achieve long-term goals } \\
\text { - Specifying short-term goals } \\
\text { - Choosing a planner }\end{array}$ \\
\hline 3 & Time management & $\begin{array}{l}\text { Managing my time } \\
\text { effectively }\end{array}$ & $\begin{array}{l}\text { - Using a planner } \\
\text { - Setting priorities for things to do } \\
\text { - Making a weekly/daily plan }\end{array}$ \\
\hline 4 & $\begin{array}{l}\text { Emotion regulation } \\
\text { and control }\end{array}$ & $\begin{array}{l}\text { Controlling my } \\
\text { emotions and stress }\end{array}$ & $\begin{array}{l}\text { - Recognizing my emotions } \\
\text { - Lowering my emotional discomfort index } \\
\text { - Strategies to manage my stress }\end{array}$ \\
\hline 5 & Cognitive flexibility & $\begin{array}{l}\text { Thinking and acting } \\
\text { flexibly }\end{array}$ & $\begin{array}{l}\text { - Noticing inconsistencies between the situation and my actions or } \\
\text { recognizing the results of fixed behaviour patterns } \\
\text { - Flexibly accepting other people's advice } \\
\text { - Dealing with changes in the situation }\end{array}$ \\
\hline 6 & $\begin{array}{l}\text { Applying EF } \\
\text { to daily life }\end{array}$ & $\begin{array}{l}\text { Managing my daily life } \\
\text { using executive } \\
\text { functions }\end{array}$ & $\begin{array}{l}\text { - Taking care of personal hygiene } \\
\text { - Taking care of my health } \\
\text { - Taking care of my house } \\
\text { - Safety }\end{array}$ \\
\hline 7 & $\begin{array}{l}\text { Applying EF } \\
\text { to daily life }\end{array}$ & $\begin{array}{l}\text { Managing my finance } \\
\text { using executive } \\
\text { functions }\end{array}$ & $\begin{array}{l}\text { - Creating and keeping an account book } \\
\text { - Budgeting } \\
\text { - Managing my bank account } \\
\text { - Learning strategies for rational buying } \\
\text { - Making plans for leisure activities }\end{array}$ \\
\hline 8 & $\begin{array}{l}\text { Applying EF to social } \\
\text { and professional life }\end{array}$ & $\begin{array}{l}\text { Improving my social } \\
\text { adaptive skills using } \\
\text { executive function }\end{array}$ & $\begin{array}{l}\text { - Strategies to adapt quickly to a new environment } \\
\text { - Academic strategies at a university } \\
\text { - Organising my surrounding environment for effective learning and } \\
\text { working } \\
\text { - Strategies for controlling academic and work-related stress } \\
\text { - Choosing a job }\end{array}$ \\
\hline 9 & $\begin{array}{l}\text { Applying EF to social } \\
\text { and professional life }\end{array}$ & $\begin{array}{l}\text { Finding a job and } \\
\text { presenting myself }\end{array}$ & $\begin{array}{l}\text { - Checking the conditions of my preferred workplace } \\
\text { - Learning how to search for jobs } \\
\text { - Learning about job application documents (CV, personal statement } \\
\text { etc.) } \\
\text { - Preparing for a job interview }\end{array}$ \\
\hline 10 & $\begin{array}{l}\text { Applying EF to social } \\
\text { and professional life }\end{array}$ & $\begin{array}{l}\text { How to have a successful } \\
\text { interview and work life }\end{array}$ & $\begin{array}{l}\text { - Job interview attitude and manners } \\
\text { - How to manage my interview anxiety } \\
\text { - How to have a successful work life } \\
\text { - Responsibilities as a working professional }\end{array}$ \\
\hline
\end{tabular}

EF: executive functions, CV: curriculum vitae

\section{Measures}

\section{The Korean version of Barkley Deficits in Executive Functioning Scale (K-BDEFS)}

The BDEFS was developed by Barkley ${ }^{30}$ to measure the EF of adults in everyday life. Eighty-nine items of the BDEFS are divided into five $\mathrm{EF}$ factors: time management, organization, self-restraint, self-motivation, and regulation of emotion. Items are rated between 1 and 4 , with a higher score representing more problematic EF skills. The BDEFS has been translated and validated in South Korea (Cronbach's $\alpha=0.98$ ). ${ }^{31}$ Although the K-BDEFS is meant to be based upon self-reports, participants and caregivers were asked to complete the questionnaire to obtain a more objective EF measure. 


\section{Cognitive Flexibility Inventory (CFI)}

The CFI is a measure of cognitive flexibility and is divided into items under the alternative subdomain, which measures the ability to suggest alternative solutions to an event, or the control subdomain, which measures the ability to perceive a difficult situation as controllable. ${ }^{32}$ Items are rated on a scale of $1-7$, and a higher score represents better cognitive flexibility. This study used the Korean version of the CFI that was translated and validated by Huh. ${ }^{33}$ One item with a low factor loading has been eliminated during the validation process, resulting in a total of 19 items (Cronbach's $\alpha$ for total score $=0.862){ }^{34}$

\section{The Korean version of Vineland Adaptive Behavior Scale-II (K-Vineland-II)}

Vineland-II is a measure of adaptive behavior, personal and social skills relevant to independent living from birth to 90 years. ${ }^{35}$ The Korean translated version of the Vineland-II was used in the study. ${ }^{36}$ Domains for adults include communication, daily living skills, and socialization. A total of 433 items are rated from $0-2$, with a higher score indicating better use of the skills. The internal consistency of the K-Vineland-II was high for all four domains (Cronbach's $\alpha=0.89-0.97) .{ }^{36} \mathrm{Al}$ though caregivers generally complete the K-Vineland-II, both parents and participants completed the questionnaire to see how adults with ASD perceive the change in their adaptive behavior.

\section{Community Integration Skills Assessment-2 (CISA-2)}

The CISA-2 was developed by Kim et al. ${ }^{37}$ based on the Street Survival Skills Questionnaire (SSSQ) of the McCarronDial Vocational Evaluation System. The CISA-2 aims to measure adaptive skills necessary for individuals with developmental disorders to be integrated into the local community (Cronbach's $\alpha=0.878$ ). ${ }^{37}$ The test is administered face-to-face and includes 161 items, divided into ten subtests based on three subdomains.

\section{Assessment procedures}

The participants and their parents attended a group meeting one week before the intervention to complete the questionnaires. Parents were asked to complete the K-BDEFS and K-Vineland-II, while the participants were asked to complete K-BDEFS, CFI, and K-Vineland-II. Participants were also individually administered the CISA-2 in a separate room. Before the start of the 6th session, participants completed the KBDEFS again as a mid-intervention measure. Post-intervention measures, which were the same as the pre-intervention measures, were taken one week after the intervention was completed. Because of the COVID-19 outbreak, while most post-intervention tests were administered in-person, some participants completed the assessments online.

Participants completed the program satisfaction and difficulty ratings after each session and an overall rating upon completion of the 10-week intervention program using a 5-point Likert scale (Satisfaction: $1=$ not satisfied, $3=$ somewhat, $5=$ very satisfied; Difficulty: $1=$ very easy, $3=$ moderate difficulty, $5=$ very difficult).

\section{Statistical analysis}

Differences between pre- and post-intervention outcome variables were analyzed using Wilcoxon signed-rank tests. Spearman rho's coefficient was used to explore potential correlations between IQ and EF or adaptive skills. The decision to use non-parametric tests was based on the small sample size available $(n=7)$. For the participant-completed K-BDEFS, the difference between pre- and mid-, mid- and post-, and pre- and post-intervention outcome scores were analyzed. Statistical analyses were performed using SPSS Statistics 25 (IBM Corp., Armonk, NY, USA). The confidence interval was set at $95 \%$.

\section{RESULTS}

\section{Subjects}

There were initially eight participants, ranging between 19- to 25-year-olds, who met the inclusion criteria and completed the pre-intervention assessment. All participants surpassed the ASD diagnostic threshold in ADOS and ADI-R. One participant dropped out before starting the program due to scheduling conflicts resulting in all-male participants with an average age of 20.29 and IQ of 92.57 (range 76-120). While there was a large IQ range, we found no evidence of a significant correlation between the total and subdomain scores of IQ and K-BDEFS ( $\mathrm{p}=0.41-1)$ or K-Vineland-II ( $\mathrm{p}=0.09-1)$. All participants were dependent and lived with their parents during the time enrolled in the intervention program. Table 3 provides detailed information on participant characteristics.

\section{Executive function measures}

For the self-reported K-BDEFS, there were significant differences between the pre- and post-intervention scores for the total scores as well as time management, organization, self-restraint, and regulation of emotion subdomains $(\mathrm{p}<0.05)$ but not the self-motivation subdomain $(\mathrm{p}=0.22)$. While there were significant differences found in the total score of the K-BDEFS and subdomains of time management, organization, and selfrestraint between mid- and post-intervention scores $(\mathrm{p}<0.05$, Table 4, Figure 1), there were no differences between pre- and mid-intervention scores. There were no significant differences found in the pre- and post-intervention total score $(\mathrm{z}=-0.67$, 
Table 3. Participant demographic characteristics

\begin{tabular}{ccclcc}
\hline Participant & Sex & Age & \multicolumn{1}{c}{ Education } & FSIQ & Job \\
\hline 1 & Male & 22 & Enrolled in university & 76 & Student \\
2 & Male & 21 & Enrolled in university & 96 & Student \\
3 & Male & 19 & Dropped out of university & 107 & Unemployed \\
4 & Male & 19 & About to start university & 85 & Student \\
5 & Male & 20 & Enrolled in university & 84 & Student \\
6 & Male & 20 & Enrolled in university & 80 & Part-time job \\
7 & Male & 21 & High school graduate
\end{tabular}

FSIQ: full scale intelligence quotient

Table 4. Comparisons of pre-, mid-, and post-intervention scores of the Barkley Deficits in Executive Functioning Scale

\begin{tabular}{|c|c|c|c|c|c|c|c|c|c|}
\hline \multirow{2}{*}{ Subdomain } & \multirow{2}{*}{$\begin{array}{c}\text { Pre } \\
M(S D)\end{array}$} & \multirow{2}{*}{$\begin{array}{c}\text { Mid } \\
\text { M (SD) }\end{array}$} & \multirow{2}{*}{$\begin{array}{c}\text { Post } \\
\mathrm{M}(\mathrm{SD})\end{array}$} & \multicolumn{2}{|c|}{ Pre-mid } & \multicolumn{2}{|c|}{ Mid-post } & \multicolumn{2}{|c|}{ Pre-post } \\
\hline & & & & $\mathrm{z}$ & $\mathrm{p}$ & $\mathrm{z}$ & $\mathrm{p}$ & $\mathrm{z}$ & $\mathrm{p}$ \\
\hline Time management & $58.00(19.90)$ & $55.57(17.66)$ & $44.71(13.88)$ & -0.95 & 0.34 & -2.37 & $0.02^{*}$ & -2.21 & $0.03^{*}$ \\
\hline Organization & $63.57(24.20)$ & $61.14(21.39)$ & $52.43(19.33)$ & -0.96 & 0.34 & -2.20 & $0.04^{*}$ & -2.37 & $0.02 *$ \\
\hline Self-restraint & $45.57(15.44)$ & $46.00(15.55)$ & $41.00(14.17)$ & -0.32 & 0.75 & -2.37 & $0.02^{*}$ & -2.38 & $0.02 *$ \\
\hline Self-motivation & $27.29(11.94)$ & $25.43(10.95)$ & $22.86(8.38)$ & -0.11 & 0.93 & -1.58 & 0.11 & -1.22 & 0.22 \\
\hline Regulation of emotions & $33.43(14.71)$ & $32.00(13.30)$ & $30.00(12.97)$ & -1.51 & 0.13 & -1.36 & 0.18 & -2.02 & $0.04^{*}$ \\
\hline Total & $227.86(81.48)$ & $220.14(74.47)$ & $191.00(62.83)$ & -1.36 & 0.18 & -2.37 & $0.02 *$ & -2.37 & $0.02^{*}$ \\
\hline
\end{tabular}

${ }^{*} \mathrm{p}<0.05$, Wilcoxon signed-rank tests. SD: standard deviation

$\mathrm{p}>0.05$ ) and subdomain scores of CFI (alternative $\mathrm{z}=-0.68$, control $\mathrm{z}=-0.77, \mathrm{p}>0.05)$.

\section{Adaptive function measures}

For the K-Vineland-II questionnaire completed by participants, there were significant differences in the pre- and postintervention total scores $(\mathrm{p}=0.03)$ and the daily living skills domain ( $\mathrm{p}=0.02)$, but not in the communication and socialization domain ( $p>0.05$, Table 5 ). When adaptive functioning was measured utilizing the CISA-2 assessment, a significant difference was found between the pre- and post-intervention total score ( $\mathrm{p}=0.03$, Table 5 ). However, no differences were found in any of the subdomains of the CISA-2.

\section{Caregiver-reported measures}

While the caregiver-reported K-BDEFS showed significant differences in the opposite direction of the regulation of emotion subdomain score $(\mathrm{p}=0.05)$, no other differences were detected in the total or subdomain scores by the K-Vineland-II ( $p>0.005$, Table 5).

\section{Program adherence and satisfaction}

All seven participants completed the 10 -week intervention program. While the program's overall satisfaction after the intervention was rated as 4.43 , the mean satisfaction level for each of the ten sessions was 3.86 , indicating above moderate

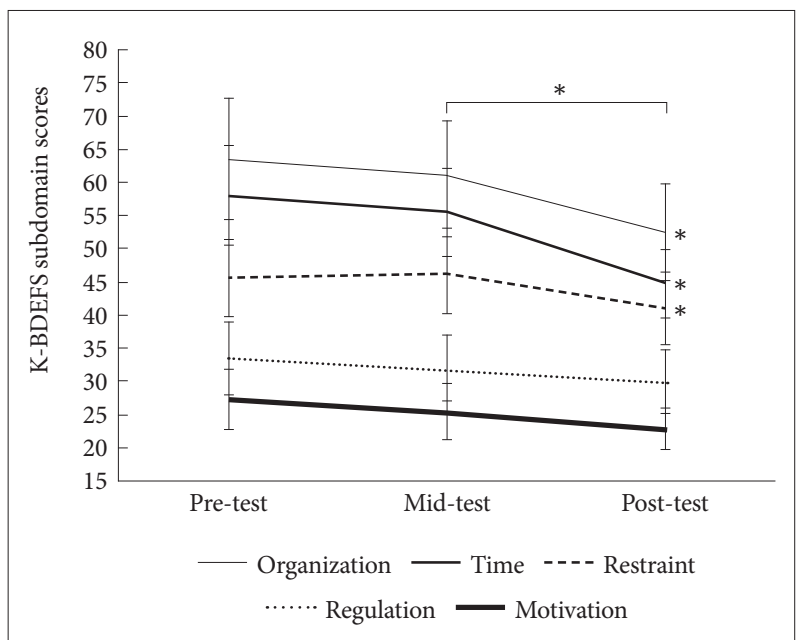

Figure 1. Change in the Barkley Deficits in Executive Functioning Scale subdomain score. ${ }^{*} p<0.05$.

satisfaction. The mean difficulty level was 2.67 , which implies slightly below moderate difficulty.

\section{DISCUSSION}

The current study provides preliminary evidence for the intervention program's validity and feasibility to improve everyday EF and adaptive functioning in adults with ASD. As hypothesized, everyday EF based on self-report by adults with 
Table 5. Pre-intervention and post-intervention outcome variables

\begin{tabular}{|c|c|c|c|c|}
\hline \multirow{2}{*}{ Variable } & \multicolumn{2}{|c|}{ Mean (SD) } & \multirow{2}{*}{$\mathrm{Z}$} & \multirow{2}{*}{$\mathrm{p}$} \\
\hline & Pre & Post & & \\
\hline \multicolumn{5}{|l|}{ Self } \\
\hline \multicolumn{5}{|l|}{ K-VABS-II } \\
\hline Communication & $78.86(11.52)$ & $83.29(13.28)$ & -0.84 & 0.40 \\
\hline Daily living skills & $78.29(13.15)$ & 85.57 (14.75) & -2.37 & $0.02^{*}$ \\
\hline Socialization & $69.14(7.90)$ & $72.14(5.15)$ & -1.61 & 0.11 \\
\hline Total & $70.00(11.31)$ & $74.86(10.21)$ & -2.21 & $0.03^{*}$ \\
\hline \multicolumn{5}{|l|}{ CISA-2 } \\
\hline Basic living & $112.00(4.51)$ & $113.14(3.58)$ & -1.19 & 0.23 \\
\hline Social independence & $117.86(1.68)$ & $120.14(1.46)$ & -1.75 & 0.08 \\
\hline Occupational life & $110.86(8.09)$ & $117.14(6.01)$ & -1.83 & 0.07 \\
\hline Total & $114.57(2.94)$ & $117.43(1.81)$ & -2.21 & $0.03^{*}$ \\
\hline \multicolumn{5}{|l|}{ Parent } \\
\hline \multicolumn{5}{|l|}{ K-VABS-II } \\
\hline Communication & $73.29(3.40)$ & $74.29(8.12)$ & -.511 & 0.61 \\
\hline Daily living skills & $75.71(6.32)$ & $82.00(16.37)$ & -1.36 & 0.17 \\
\hline Socialization & $66.71(5.41)$ & $68.00(7.00)$ & -0.68 & 0.50 \\
\hline Total & $66.57(3.36)$ & $69.14(9.89)$ & -0.59 & 0.55 \\
\hline \multicolumn{5}{|l|}{ K-BDEFS } \\
\hline Time management & $52.86(11.36)$ & $49.71(10.98)$ & -1.10 & 0.27 \\
\hline Organization & $57.71(8.81)$ & $53.86(11.07)$ & -1.53 & 0.13 \\
\hline Self-restraint & $41.71(9.26)$ & $42.43(10.06)$ & -0.51 & 0.61 \\
\hline Self-motivation & $25.29(6.65)$ & $26.57(8.89)$ & -0.68 & 0.50 \\
\hline Regulation of emotions & $25.29(6.65)$ & $32.86(13.07)$ & -1.99 & $0.05^{*}$ \\
\hline Total & $202.71(32.98)$ & $205.43(44.46)$ & -0.40 & 0.74 \\
\hline
\end{tabular}

${ }^{*} \mathrm{p}<0.05$, Wilcoxon signed-rank tests. SD: standard deviation, K-VABS-II: Korean version of Vineland Adaptive Behavior Scale-II, CISA-2: Community Integration Skills Assesment-2, K-BDEFS: Korean version of Barkley Deficits in Executive Functioning Scale

ASD and adaptive functioning measured by self-reports and assessment instruments demonstrated significant improvements. However, such findings were not replicated by parentreport measures.

Most of the EF areas aimed by the intervention, such as time management, organization, and regulation of emotion, showed a positive change after the intervention, providing evidence that the intervention was effective in improving the targeted cognitive abilities of the EF. However, there was no difference measured in the areas of self-motivation and cognitive flexibility. These improvements are similar to the SUCCESS intervention, ${ }^{28}$ where they found improvements in behavioral regulation, planning, organization, and inhibition but no significant improvements in cognitive flexibility. This could be because time management, organization, self-restraint, and regulation of emotion are areas that are more directly measurable through external behaviors, while motivation and cognitive flexibility are areas that involve more internal cognitive processes. Be- havioral changes can be achieved relatively faster than cognitive changes, which may be why the current study found differences in more behaviorally measurable areas. While ten weeks may have been enough to cause behavioral changes, it may have been too short to induce quantifiable changes in internal cognitive processes. Such results are in line with Eack et al., ${ }^{27}$ who found cognitive flexibility improvements after nine months of intervention.

We found significant improvements in the daily living skills subdomains by the self-reported K-Vineland-II measure but not in the communication and socialization domains. Enhancement in daily living skills provides evidence that the current intervention effectively applies the EF skills learned to enhance daily adaptive skills. These results are similar to the improvements in functional daily living skills (such as hygiene, cooking, finances, household etc.) found in the intervention study by Baker-Ericzén et al. ${ }^{28}$ Because the intervention was not directly aimed at improving social communication skills, no 
differences in communication and socialization of adaptive skills were unsurprising. An objective instrument, CISA-2, assessed significant results in adaptive skills. Although there were no differences found in the subdomains, the most considerable change with approaching significance was found in the subdomain of occupational life and suggested modifications to be made in the program to emphasize this area.

While adults with ASD perceived positive changes, such results were not replicated by the parents. In line with the findings from Baker-Ericzén et al., ${ }^{28}$ caregiver-reports found no differences in $\mathrm{EF}$ and adaptive functioning. Other intervention programs where parents reported significant changes within individuals with ASD were based on parent-assisted programs such as PEERS. ${ }^{38,39}$ Parents may be more sensitive in detecting changes as they are more involved with the intervention by learning and practicing the same materials taught to individuals with ASD. However, as parents were unaware of the topics being covered in our intervention and not knowing which features to focus on, they may have overlooked subtle behavioral differences. Hence, additional methods to facilitate parents' indirect involvement are being considered, which will enable caregivers to provide support and become more sensitive in tracking changes.

The significant worsening of emotion regulation found by the caregiver-reports was unexpected. The FGI identified emotion regulation as an important target area, and it may be the most noticeable behavior to caregivers. High-functioning adults with ASD experience a service cliff during the transitional age and are less likely to engage in daytime activities. Additionally, as most individuals don't have independent living arrangements, they spend the majority of their time with families. Considering that our intervention took place during winter break for students who were attending university, it is possible that the adults with ASD spent more time at home, which increased the risk of being involved in minor conflicts with their caregivers. Therefore, such results imply that parents could have attributed the frequent quarrels to the participant as having experienced more difficulties with emotion regulation. To complement this area, the modified intervention content during the randomized controlled trial will fortify the education material for the emotion regulation domain by including frequent repetition and activity exercises to practice the application of skills in diverse situations.

The strength of the current intervention is its effectiveness in inducing significant changes in everyday EF and adaptive skills in a relatively short period. Considering that previous intervention studies lasted from 6 months to 18 months, ${ }^{27,28}$ this significantly short time frame can reduce the cost and make the intervention more accessible for adults with ASD who may have limited availability due to studies and other commitments.

The results should be interpreted with caution, as the sample size of the current pilot study was small and does not include a control group. This is due to the current study being a pilot trial to test the intervention's validity and feasibility before administering a randomized controlled trial. Another limitation of the study was the lack of a more objective measure of everyday EF, with all the EF measures and most adaptive skills measures relying on self- or caregiver-reported questionnaires. Although previous intervention studies incorporated neurocognitive tests as an outcome measure, 27 our study did not include such assessments because our focus was on the ecologically valid EF skill improvements used in everyday life. Although a more objective measure of everyday EF skills would have been advantageous, a positive change in adaptive skills as measured by CISA-2 adds some evidence to the objectivity of the enhancement in the targeted skills.

Although significant findings have been achieved during the 10-weekly sessions, the facilitators felt that the later sessions, which focused on applying everyday EF skills in daily situations, were rushed due to time constraints. Therefore, we plan on expanding the program content into a 12-week intervention program that will be tested as a randomized controlled trial.

In conclusion, the current pilot study provides good evidence for the novel intervention programs' validity and feasibility to enhance everyday EF and adaptive skills in adults with ASD. Areas of improvement include time management, organization, self-restraint, regulation of emotions, as well as adaptive functioning, and daily living skills.

\section{Acknowledgments}

This study was funded and provided by the facilities at Seoul National University Bundang Hospital (02-2018-049).

\section{Conflicts of Interest}

The authors have no potential conflicts of interest to disclose.

\section{Author Contributions}

Conceptualization: Joo Hyun Kim, Paul Kyuman Chae, Hee Jeong Yoo. Data curation: Joo Hyun Kim, Young Ah Kim, Hwi Bin Cho, Han Bit Lee, Ji Hye Park. Formal analysis: Young Ah Kim, Han Bit Lee. Funding acquisition: Hee Jeong Yoo. Investigation: Joo Hyun Kim, Jung In Lim, Ji Hye Park, Min Hee Hong. Methodology: Joo Hyun Kim, Hee Jeong Yoo. Project administration/Intervention facilitation: Joo Hyun Kim. Intervention assistant: Hwi Bin Cho, Han Bit Lee, Ji Hye Park, Young Ah Kim. Supervision: Paul Kyuman Chae, Hee Jeong Yoo. Writing_original draft: Young Ah Kim, Joo Hyun Kim. Writing-review \& editing: Joo Hyun Kim, Young Ah Kim, Da-Yea Song, Hee Jeong Yoo.

\section{ORCID iDs}

Joo Hyun Kim

Young Ah Kim

Da-Yea Song

Hwi Bin Cho https://orcid.org/0000-0002-9000-0092 https://orcid.org/0000-0002-7144-4739 https://orcid.org/0000-0002-5895-3125 https://orcid.org/0000-0003-4166-4447 
Han Bit Lee Ji Hye Park Jung In Lim Min Hee Hong Paul Kyuman Chae Hee Jeong Yoo

https://orcid.org/0000-0002-5853-1053 https://orcid.org/0000-0003-0232-4394 https://orcid.org/0000-0003-0180-9736 https://orcid.org/0000-0002-8632-6460 https://orcid.org/0000-0002-4158-4968 https://orcid.org/0000-0003-0521-2718

\section{REFERENCES}

1. Lai MC, Kassee C, Besney R, Bonato S, Hull L, Mandy W, et al. Prevalence of co-occurring mental health diagnoses in the autism population: a systematic review and meta-analysis. Lancet Psychiatry 2019; 6:819-829.

2. Baio J, Wiggins L, Christensen DL, Maenner MJ, Daniels J, Warren Z, et al. Prevalence of autism spectrum disorder among children aged 8 years - autism and developmental disabilities monitoring network, 11 sites, United States, 2014. MMWR Surveill Summ 2018;67:1-23.

3. Howlin P, Goode S, Hutton J, Rutter M. Adult outcome for children with autism. J Child Psychol Psychiatry 2004;45:212-229.

4. Taylor JL, Seltzer MM. Employment and post-secondary educational activities for young adults with autism spectrum disorders during the transition to adulthood. J Autism Dev Disord 2011;41:566-574.

5. Camm-Crosbie L, Bradley L, Shaw R, Baron-Cohen S, Cassidy S. 'People like me don't get support': Autistic adults' experiences of support and treatment for mental health difficulties, self-injury and suicidality. Autism 2018;23:1431-1441.

6. Rabbitt P. Methodology of Frontal and Executive Function. Routledge: Psychology Press; 1997.

7. Roberts A, Robbins T, Weiskrantz L. Executive and Cognitive Functions of the Prefrontal Cortex. Oxford: Oxford University Press; 1998.

8. Stuss D, Knight R. Prefrontal Cortex: the Present and the Future. In: Stuss D, Knight R, Editors. Principles of Frontal Lobe Function. Oxford: Oxford University Press; 2002. DOI:10.1093/acprof:o so/9780195134971.003.0034.

9. Burgess PW, Alderman N, Forbes C, Costell A, Coates LM, Dawson DR, et al. The case for the development and use of "ecologically valid" measures of executive function in experimental and clinical neuropsychology. J Int Neuropsychol Soc 2006;12:194-209.

10. Gardiner E, Iarocci G. Everyday executive function predicts adaptive and internalizing behavior among children with and without autism spectrum disorder. Autism Res 2018;11:284-295.

11. O'Hearn K, Asato M, Ordaz S, Luna B. Neurodevelopment and executive function in autism. Dev Psychopathol 2008;20:1103-1132.

12. Rosenthal M, Wallace GL, Lawson R, Wills MC, Dixon E, Yerys BE, et al. Impairments in real-world executive function increase from childhood to adolescence in autism spectrum disorders. Neuropsychology 2013;27:13-18.

13. Hill EL. Executive dysfunction in autism. Trends Cogn Sci 2004;8:26-32.

14. Zimmerman DL, Ownsworth T, O’Donovan A, Roberts J, Gullo MJ. Independence of hot and cold executive function deficits in high-functioning adults with autism spectrum disorder. Front Hum Neurosci 2016;10:24.

15. Shmulsky S, Gobbo K. Autism spectrum in the college classroom: strategies for instructors. Commun College J Res Pract 2013;37:490-495.

16. Perry N. Adults on the Autism Leave the Nest: Achieving Supported Independence. London: Jessica Kingsley Publishers; 2009.

17. Kraper CK, Kenworthy L, Popal H, Martin A, Wallace GL. The gap between adaptive behavior and intelligence in autism persists into young adulthood and is linked to psychiatric co-morbidities. J Autism Dev Disord 2017;47:3007-3017.

18. Tassé MJ, Schalock RL, Balboni G, Bersani H Jr, Borthwick-Duffy SA, Spreat S, et al. The construct of adaptive behavior: its conceptualization, measurement, and use in the field of intellectual disaability. Am J Intellect Dev Disabil 2012;117:291-303.

19. Pugliese CE, Anthony L, Strang JF, Dudley K, Wallace GL, Kenworthy
L. Increasing adaptive behavior skill deficits from childhood to adolescence in autism spectrum disorder: role of executive function. J Autism Dev Disord 2015;45:1579-1587.

20. Tillmann J, San José Cáceres A, Chatham CH, Crawley D, Holt R, Oakley $\mathrm{B}$, et al. Investigating the factors underlying adaptive functioning in autism in the EU-AIMS Longitudinal European Autism Project. Autism Res 2019;12:645-657.

21. Adreon D, Durocher JS. Evaluating the college transition needs of individuals with high-functioning autism spectrum disorders. Interv Sch Clin 2007;42:271-279.

22. Oswald TM, Winder-Patel B, Ruder S, Xing G, Stahmer A, Solomon M. A pilot randomized controlled trial of the ACCESS program: a group intervention to improve social, adaptive functioning, stress coping, and self-determination outcomes in young adults with autism spectrum disorder. J Autism Dev Disord 2018;48:1742-1760.

23. Nadig A, Flanagan T, White K, Bhatnagar S. Results of a RCT on a transition support program for adults with ASD: effects on self-determination and quality of life. Autism Res 2018;11:1712-1728.

24. Ruble LA, McGrew JH, Toland M, Dalrymple N, Adams M, Snell-Rood C. Randomized control trial of COMPASS for improving transition outcomes of students with autism spectrum disorder. J Autism Dev Disord 2018;48:3586-3595.

25. Pugliese CE, White SW. Brief report: problem solving therapy in college students with autism spectrum disorders: feasibility and preliminary efficacy. J Autism Dev Disord 2014;44:719-729.

26. White SW, Richey JA, Gracanin D, Coffman M, Elias R, LaConte S, et al. Psychosocial and computer-assisted intervention for college students with autism spectrum disorder: preliminary support for feasibility. Educ Train Autism Dev Disabil 2016;51:307-317.

27. Eack SM, Greenwald DP, Hogarty SS, Bahorik AL, Litschge MY, Mazefsky CA, et al. Cognitive enhancement therapy for adults with autism spectrum disorder: results of an 18-month feasibility study. J Autism Dev Disord 2013;43:2866-2877.

28. Baker-Ericzén MJ, Fitch MA, Kinnear M, Jenkins MM, Twamley EW, Smith L, et al. Development of the supported employment, comprehensive cognitive enhancement, and social skills program for adults on the autism spectrum: results of initial study. Autism 2017;22:6-19.

29. Miles M, Huberman M. Qualitative Data Analysis. Thousand Oaks, CA: SAGE Publications; 1994.

30. Barkley R. Barkley Deficits in Executive Functioning Scale (BDEFS) Manual. New York, NY: Guilford Press; 2011.

31. Hwang S, Hong S, Kim J. Reliability and validity of the Korean version of Barkley Deficits in Executive Functioning Scale (K-BDEFS). Kor J Clin Psychol 2016;35:519-539.

32. Dennis JP, Vander Wal JS. The cognitive flexibility inventory: instrument development and estimates of reliability and validity. Cognit Ther Res 2010;34:241-253.

33. Huh S. Role of Cognitive Flexibility in the Relationship between Perfectionism and Psychological Maladjustment [Master's Thesis]. Seoul: Seoul National University; 2011.

34. Kim S, Hyun M. The mediating effect of cognitive flexibility in the relationship between emotional clarity and emotion regulation: comparison of self-reported and task measurement of cognitive flexibility. Korean J Str Res 2018;26:159-165.

35. Volkmar F. Vineland Adaptive Behavior Scales, Second Edition. In: Volkmar F, Editor. Encyclopedia of Autism Spectrum Disorders. New York, NY: Springer; 2013. DOI: https://doi.org/10.1007/978-1-44191698-3_224.

36. Hwang S, Kim J, Hong S, Bae S, Cho S. Standardization study of the Korean Vineland Adaptive Behavior Scales-II (K-Vineland-II). Kor J Clin Psychol 2015;34:851-876.

37. Kim D, Jang S, Kim J, Park H. The psychometric adequacy of revision of Community Integration Skills Assessment. J Intellect Disabil Res 2017;19:1-20.

38. McVey AJ, Dolan BK, Willar KS, Pleiss S, Karst JS, Casnar CL, et al. A 
replication and extension of the PEERS ${ }^{\circledR}$ for young adults social skills intervention: examining effects on social skills and social anxiety in young adults with autism spectrum disorder. J Autism Dev Disord 2016; 46:3739-3754.
39. Laugeson EA, Gantman A, Kapp SK, Orenski K, Ellingsen R. A randomized controlled trial to improve social skills in young adults with autism spectrum disorder: the UCLA PEERS $\left({ }^{\circledR}\right)$ Program. J Autism Dev Disord 2015;45:3978-3989. 